\title{
Health-Care Workers' Compliance with Infection Prevention Guidelines and Associated Factors in Hadiya Zone, Southern Ethiopia: Hospital Based Cross Sectional Study
}

\author{
Yohannes T1*, Kassa G², Laelago $\mathrm{T}^{3}$ and Guracha $\mathrm{E}^{4}$ \\ ${ }^{1}$ College of medicine and health sciences, Hawassa University, Ethiopia \\ ${ }^{2}$ Department of health information technology, Hossana College of Health \\ Science, Ethiopia
}

${ }^{3}$ School of public health, Wolaita sodo University, Ethiopia

${ }^{4}$ Department of Medical Laboratory Technology, Hossana College of Health Sciences, Ethiopia

*Corresponding author: Tadele Yohannes, College of medicine and health sciences, Hawassa University, Hawassa, Ethiopia, Tel: +251916463961 Email: tadejoha@gmail.com

\section{Abstract}

Background: Infections in health care facilities have become a major health problem, especially in the health institutions located in developing countries. The objective of this study was assessing health-care workers' compliance with Infection prevention guidelines and factors that influence compliance in Hospitals of Hadiya Zone, Southern Ethiopia, 2017.

Methods: A hospital based cross-sectional study was conducted from May to June 2017. To draw a total sample of size 279 simple random sampling technique was used. Data were entered using Epi-Data version 3.1 and exported to SPSS version 20 for analysis. Binary logistic regression analysis was used to see significance of association between the outcome and independent variables. Odds ratios at 95\% CI were computed to measure the strength of the association between the outcome and the explanatory variables. P-value $<0.05$ was considered as a statistically significant.

Results: The findings of this study showed that the overall compliance of health care workers with infection prevention guidelines was 15.0\% (95\%CI: 11.0\%, 19.0\%). Being female (AOR: 2.962, 95\%CI: $(1.342,6.535$ )), positive attitude towards IP guidelines (AOR: 3.130, 95\%CI: (1.192, 8.224)), access to IP guidelines (AOR: 2.820, 95\%CI: (1.076, 7.389)), training on IP guidelines (AOR: 2.262, 95\%CI: $(1.008,5.078)$ ) were significantly associated with compliance with IP guidelines.

Conclusion: In this study the overall compliance level of the health care workers to infection prevention guide lines was very low. Being female, attitude towards infection prevention guidelines, accessibility of personal protective equipment's and training were factors significantly associated with compliance with infection prevention guidelines. 


\section{Epidemiology international journal}

Continuous training on infection prevention guidelines should be given to health care workers, especially for males. Accessibility of infection prevention materials and equipments in the hospitals should get due attention.

Keywords: Compliance; Health care workers; Infection Prevention; Ethiopia

Abbreviations: CI: Confidence Interval; HAI: Hospital Acquired Infection; HCWs: HealthCare workers; HBV: Hepatitis B Virus; HCV: Hepatitis C Virus; HIV: Human immune deficiency virus; IP: Infection Prevention; PPE: Personal Protective Equipment; SPSS: Statistical Package for Social Sciences.

\section{Background}

Health care acquired infection (HAI) is an infection occurring in a patient in a hospital or other health care facility in whom the infection was not present or incubating at the time of admission. This includes infections acquired in the health care facilities but appearing after discharge, and also occupational infections among staff of the facilities [1].

The most common pathogens that cause Nosocomial infections are staphylococcus aureus, Pseudomonas aeruginosa, and E. coli which are transmitted through different modes like contaminated hands of health care workers and contaminated instruments [2].

HAIs remain as the most frequent adverse event in any health care delivery system and affect millions of people each year, leading to significant morbidity and mortality [3].

Nosocomial (hospital-acquired) infections are a significant problem throughout the world and are increasing at alarming rate [4].

The Institute of Medicine reported that adverse events affect approximately 2 million patients each year in the United States, resulting in 90,000 deaths and an estimated \$4.5-5.7 billion per year in additional costs for patient care [5].

Between 2002 and 2009 HAI prevalence increased by $11.7 \%$ in a network of major Canadian hospitals [6]. Data from American hospitals demonstrated that HAIs alone account for an estimated 1.7 million infections within a year. The same data also revealed 98,987 HAIs associated deaths; of these, $36.3 \%$ were for pneumonia, $31 \%$ for blood stream infections, $13.2 \%$ for urinary tract infections, $8.3 \%$ for surgical site infections, and $11.2 \%$ for infections of other sites [7]. Although a wellestablished data were not available regarding the burden of HAIs in Africa, a systematic review done in the region showed that its magnitude would be much higher than in the developed nations [8].

Percutaneous exposures to blood and body fluids through contaminated needle pricks and other sharps are an important occupational hazard for morbidity and mortality from infections with blood-borne pathogens among health care workers. It is estimated that $2.5 \%$ of Human Immuno deficiency Virus (HIV) cases and $40 \%$ of Hepatitis B virus (HBV) and Hepatitis B virus (HCV) cases among HCWs worldwide are the result of this form of exposure [9].

Sex of health care workers, infection risk perception, training on standard precautions, accessibility of personal protective equipment and management are considered as major factors influencing compliance to infection prevention guidelines [2].

Nosocomial infection rates range from as low as $1 \%$ in a few countries in Europe and the Americas to more than $40 \%$ in parts of Asia, Latin America and subSaharan [10].

In many developing countries, however, the risk of needle stick injuries and accidental exposure to blood or body fluids is even higher [11].

Study conducted in Ethiopia revealed that significant numbers of healthcare workers (65.9\%) were exposed to blood and body fluids, of which $29 \%$ were because of needle-stick injury [9]. Preventing and controlling infection in health care facilities involves two levels of approach, standard precautions and transmissionbased precautions. Standard precautions are taken to reduce the risk of transmitting blood-borne microorganisms and other pathogens from both recognized and unrecognized sources. These precautions are used as a minimum, in the care of all patients in health care facilities and settings, regardless of their diagnoses or presumed infection status [12].

Infection prevention guidelines guide health care workers (HCWs) to practice regular hand hygiene, use personal protective equipment (PPE) like gloves, masks, eye protection, face shield and gowns when contact with mucus membranes, blood and body fluids of patients is anticipated. The guidelines also recommend correct disposal of sharps and other clinical waste [2]. In Ethiopia, the protection of patients and healthcare 


\section{Epidemiology international journal}

workers form infections inside the health care facilities has been given particular attention by the Federal Ministry of Health. Indeed, the Ministry is scaling-up its activities related to infection prevention and using all opportunities to strengthen ongoing activities. As in many of its program, the Ministry has been utilizing available evidence to establish optimal infection prevention practices in health facilities [3]. Despite a significant improvement in facility of health institutions and in the number and kind of health task forces in Ethiopia particularly in the last two decades, local reports showed that there is still high burden of HAIs [13]. On the other hand very limited evidences are available with regard to the level of compliance of healthcare workers with infection prevention guidelines and its associated factors in the country in general and in the study area in particular. There is also no study conducted before in the study area regarding compliance of health care workers with infection prevention guidelines.

Therefore, this study was aimed at assessing health care workers' compliance with infection prevention guidelines and associated factors in Hospitals of Hadiya zone, Southern Ethiopia.

\section{Methods}

\section{Study Area}

Hadiya zone is a zone in the Ethiopian southern nations, nationalities and people s' region. It is located $230 \mathrm{~km}$ from Addis Ababa and 164 from Hawassa. Hadiya zone is bordered on the south by Kambata Tambaro zone, on the south west by the Dawro zone, on the west by the Omo River which separate it from Oromia region and the Yem especial woreda, on the north by Gurage, on the north east by Silte and on the east by Halaba especial woreda. The woredas of Mirab Badawacho and Misraq Badawacho form an exclave separated from the rest of the zone by Kambata Tembaro zone. The administrative centre of the zone is hosanna. The zone covers 3542.66 square $\mathrm{km}$. Total population of Hadiya zone is $1,594,950$. Hadiya zone has 10 woredas. In the zone there are 01public general hospital, 02 primary hospitals, 61 public and 02 private health centers and 305 health posts. The functional hospitals in zone are NEMM general hospital, Homacho primary hospital and shone primary hospital. In the three hospitals there are around 482 clinical health care workers, according to Hadiya zone Health Department annual report of 2016 .

\section{Study Design and Period}

Institutional based cross-sectional study was conducted from May to June 2017

Study participants: The source population of the study was all health care workers in public Hospitals of Hadiya zone. The study population was all health care workers assigned in clinical services in public Hospitals of Hadiya zone. All health care workers who were assigned to clinical services during the study period and have regular program for direct patient care were included in the study and those health care workers who were assigned to clinical services but absent during study period and those with less than six months working experience were excluded from the study.

Sample size determination and Sampling technique: Sample size was determined using Epi info version 7 for single population proportion by considering $12 \%$ of health care workers' compliance with IP guidelines, obtained from similar previous study in Gondar [14]. Confidence level of $95 \%$ and 0.04 margin of error were taken in the calculation. Considering $10 \%$ none response rate, the determined sample size was 279 .

The required number of sample was allocated proportionally among the three hospitals found in Hadiya Zone. The sample was allocated depending on the number of health care workers in 2009 E.C. The sample assigned to each hospital was proportionally allocated to each category of health care workers. The sampling units, the health care workers, were selected by using simple random sampling technique. 


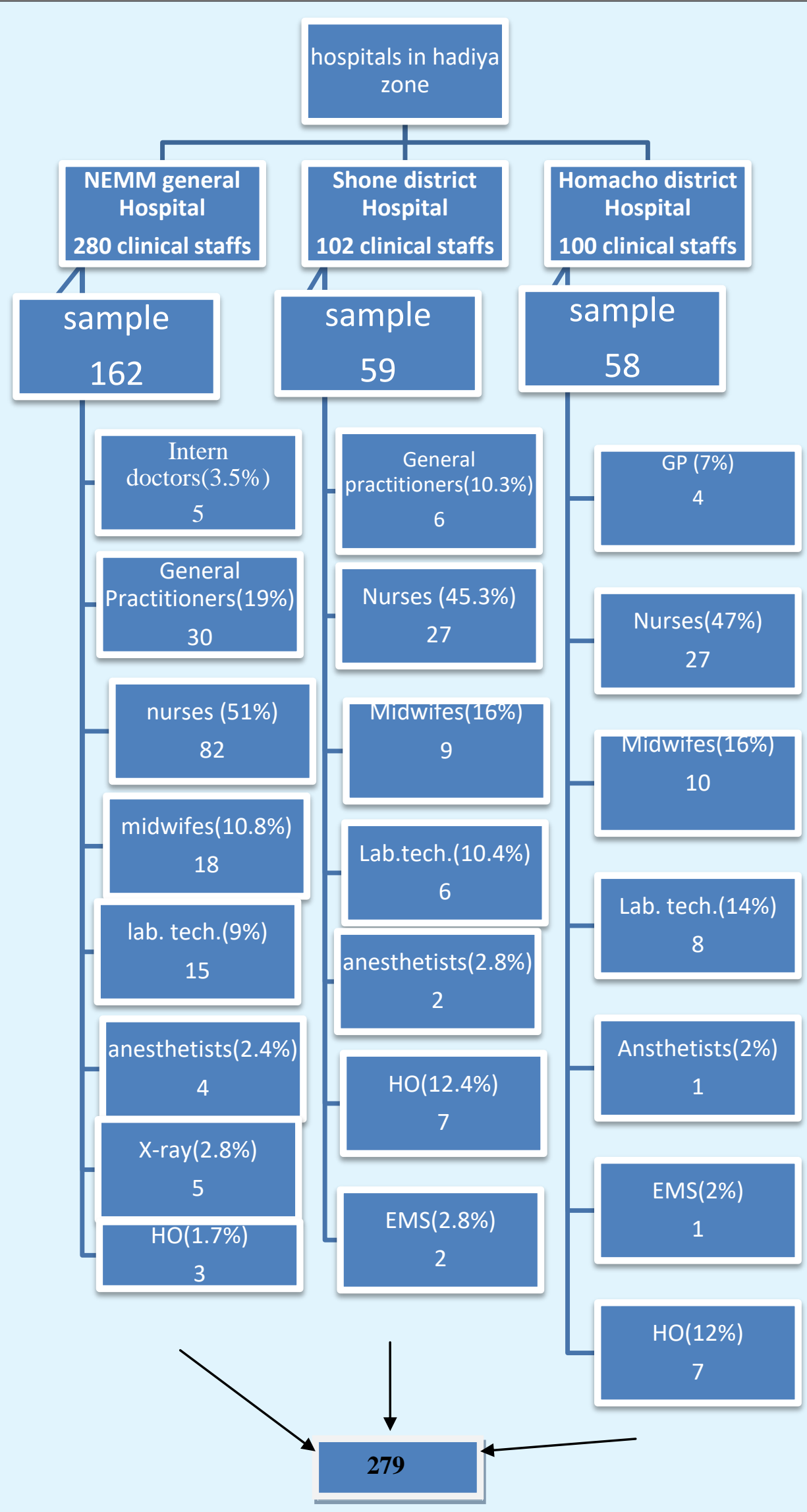

Figure 1: Schematic presentation of sampling procedure. 


\section{Epidemiology international journal}

\section{Data Collection and Measurement}

Self- administered questionnaire and observation check list was used to collect data from each study subject. The questionnaire is developed based on the Ethiopian national infection prevention and patient safety guideline [15]. The questionnaires consist of four parts. Part I consist of socio-demographic characteristics. Part II contains questionnaire that would assess health care workers compliance with IP guidelines. Part III contains about individual factors including knowledge and Attitude and part IV contains institutional factors.

Four diploma nurses were recruited as data collectors and two public health masters as supervisor, all were working in other health facilities.

Observation of the infection prevention practices was done using a check list to supplement the findings.

Compliance with IP guidelines was measured using 22 items on a 3 -point Likert scale $(1=$ seldom, $2=$ sometimes, and 3 = always). Each respondent was dichotomized as compliant/noncompliant. Those who reported that they were always compliant were taken as compliant and those who reported that they were sometimes and seldom compliant were taken as noncompliant.

Knowledge was measured using 13 items prepared to assess it. Right answer was given a value of 1 and for those incorrect answers a value of 0 was given. After computing the mean of all respondents, the mean score of each respondent was dichotomized as knowledgeable or not knowledgeable.

Knowledgeable $>=$ mean

Not knowledgeable $<$ mean

Attitude was measured using 5 items on five points Likert ( 1 = strongly disagree, 2 = Disagree, $3=$ Neutral, $4=$ Disagree and $5=$ strongly agree). After computing the mean of all respondents' responses, the mean score of each respondent was dichotomized as have positive attitude or negative attitude

Positive attitude $>=$ mean

Negative attitude $<$ mean

\section{Quality Assurance}

Training of data collectors and supervisors was made for 2 days to enable them acquire basic skills necessary for data collection and supervision, respectively. Pretesting of data collection tool was made in hospital other than the study area on $10 \%$ of sampled HCWs. Based on the results of pre-testing, data collectors was reoriented and the questionnaire was modified as necessary. The principal investigators and supervisors made a day to day on site supervision during the whole period of data collection. Completeness of the information on all variables and legibility of each filled in the questionnaire/check list was audited at the end of each day to ensure accuracy.

\section{Data Analysis}

Data were entered and cleaned using Epi-Data version 3.1 and exported to SPSS version 20 for analysis. Descriptive statistics (Frequency, mean, standard deviation, and proportion) was calculated to summarize the findings. Results were presented by tables and graphs. For knowledge and attitude scale, the items were summed up to produce composite measure and mean score was calculated for each score. For HCWs compliance to IP guidelines, those who reported that they were always compliant were taken as compliant. Those who reported that they were sometimes and seldom compliant were taken as noncompliant. Next, summation of the 22 compliance items was made. Then, the variable was re-coded and dichotomized as compliant/noncompliant. Binary logistic regression was used to predict variables which have independent association with outcome variable. Variables which have a significant association at p-value $<0.05$ in the bivariate analysis were taken to multivariate analysis to include all potential variables. Odds ratio at $95 \%$ CI was used to check for the existence and strength of association between independent and outcome variables. P-value of less than 0.05 was considered as statistical significant in the multivariate analysis.

\section{Results}

A total of 274 health care workers returned completely filled questionnaire which had a response rate of $98.2 \%$ out of 279 health care workers. Based on the finding minimum, mean and maximum ages in years of the respondents were $19,26.68$ and 57 respectively with SD of 4.18. The median work experience of the HCWs was 3 years with minimum work experience of 0.5 year and maximum work experience of 40 years. Out of the total respondents $147(53.6 \%)$ were males. Concerning Respondent's marital status, majority $170(62.0 \%)$ was single. Professionally, most frequent $135(49.3 \%)$ were nurses. Around one third 76(27.7\%) were working in outpatient department (Table 1).

\begin{tabular}{|c|c|}
\hline Variables & $\begin{array}{c}\text { Total (N and \%), N } \\
\mathbf{2 7 4}\end{array}$ \\
\hline Marital status(n=274) & \\
\hline Married & $104(38 \%)$ \\
\hline Single & $170(62 \%)$ \\
\hline Age category(n=274) & \\
\hline < 25years & $127(46.4 \%)$ \\
\hline 26-30 years & $121(44.2 \%)$ \\
\hline
\end{tabular}




\begin{tabular}{|c|c|}
\hline$>31$ years & $26(9.5 \%)$ \\
\hline \multicolumn{2}{|l|}{$\operatorname{Sex}(n=274)$} \\
\hline Male & $147(53.6 \%)$ \\
\hline Female & $127(46.4 \%)$ \\
\hline \multicolumn{2}{|l|}{ Educational Status(n=274) } \\
\hline Diploma & $132(48.2 \%)$ \\
\hline Degree & $136(49.6 \%)$ \\
\hline Masters & $4(1.5 \%)$ \\
\hline Others & $2(0.70 \%)$ \\
\hline \multicolumn{2}{|l|}{ Work experience $(n=274)$} \\
\hline$<5$ years & $197(71.9 \%)$ \\
\hline 5-10 years & $69(25.2 \%)$ \\
\hline$>10$ years & $8(2.9 \%)$ \\
\hline \multicolumn{2}{|l|}{ Profession $(n=274)$} \\
\hline General practitioners & $40(14.6 \%)$ \\
\hline Nurses & $135(49.3 \%)$ \\
\hline Midwives & $37(13.5 \%)$ \\
\hline $\begin{array}{c}\text { Laboratory } \\
\text { technologists/tech. }\end{array}$ & $35(12.8 \%)$ \\
\hline Anesthetists & $11(4 \%)$ \\
\hline Health officers & $8(2.9 \%)$ \\
\hline Others* & $8(2.8 \%)$ \\
\hline \multicolumn{2}{|l|}{$\begin{array}{l}\text { Currently assigned } \\
\text { places(wards) }\end{array}$} \\
\hline Outpatient department & $76(27.7 \%)$ \\
\hline Laboratory Room & $19(6.9 \%)$ \\
\hline Inpatient and Emergency & $31(11.4 \%)$ \\
\hline Medical ward & $24(8.8 \%)$ \\
\hline Surgical ward & $17(6.2 \%)$ \\
\hline $\begin{array}{l}\text { Gynecology and obstetric } \\
\text { ward }\end{array}$ & $39(14.3 \%)$ \\
\hline
\end{tabular}

\begin{tabular}{|c|c|}
\hline Pediatrics ward & $18(6.6 \%)$ \\
\hline Operation room & $20(7.3 \%)$ \\
\hline Radiology room & $3(1.1 \%)$ \\
\hline Intensive care unit & $17(6.2 \%)$ \\
\hline TB and ART clinic & $6(2.9 \%)$ \\
\hline Ophthalmology clinic & $4(1.6 \%)$ \\
\hline
\end{tabular}

Table 1: Socio-demographic characteristics of the respondents in Hospitals of Hadiya zone, Southern Ethiopia, July, 2017 ( $N=274)$.

*Specialists, emergency medical surgeons and x-ray professionals

Compliance level with infection prevention guidelines

From health care workers enrolled in this study, $35.0 \%, 52.2 \%, 74.8 \%$ and $42.3 \%$ always wash hands before touching a patient, before clean or aseptic procedures, after body fluid exposure and after touching a patient, respectively. Only 38.0\% were complaint to wear eye goggles whenever there is a possibility of body fluid splashing and around half $(52.8 \%)$ always provide care considering all patients as potentially infectious. Concerning waste segregation, $75.2 \%$ always segregate infectious medical wastes in yellow coloured coded dust bin. The compliance level of health care workers for never recapping needles was $69.3 \%$ (Table 2).

In this study the overall compliance level of the health care workers to infection prevention guide line was $15.0 \%$ (95\%CI: $11.0 \%, 19.0 \%)$ which was obtained by considering the components of infection prevention described below in Table 2.

\begin{tabular}{|l|l|l|l|}
\multirow{2}{*}{ Variables } & \multicolumn{2}{l|}{ Compliance level (N and \%), N =274 } \\
\cline { 2 - 4 } & seldom & Sometimes & Always \\
\hline Wash hands before touching a patient & $68(24.8 \%)$ & $110(40.1 \%)$ & $96(35.0 \%)$ \\
\hline Wash hands before clean or aseptic procedures & $37(13.5 \%)$ & $94(34.3 \%)$ & $143(52.2 \%)$ \\
\hline Wash hands after body fluid exposure & $15(5.5 \%)$ & $54(19.7 \%)$ & $205(74.8 \%)$ \\
\hline Wash hands after touching a patient & $40(14.6 \%)$ & $118(43.1 \%)$ & $116(42.3 \%)$ \\
\hline Wash hands immediately after removal of gloves & $60(21.9 \%)$ & $115(42.0 \%)$ & $99(36.1 \%)$ \\
\hline Wash hands between patient contact & $67(24.5 \%)$ & $122(44.5 \%)$ & $85(31.0 \%)$ \\
\hline Wash hands after touching patient surroundings & $54(19.7 \%)$ & $117(42.7 \%)$ & $103(37.6 \%)$ \\
\hline I provide care considering all patients as potentially infectious & $27(9.9 \%)$ & $105(38.3 \%)$ & $142(51.8 \%)$ \\
\hline $\begin{array}{l}\text { I protect myself against body fluids of all patients regardless of their } \\
\text { diagnosis }\end{array}$ & $12(4.4 \%)$ & $86(31.4 \%)$ & $176(64.2 \%)$ \\
\hline $\begin{array}{l}\text { I wear clean gloves whenever there is a possibility of exposure to any } \\
\text { body fluids }\end{array}$ & $10(3.6 \%)$ & $72(26.3 \%)$ & $192(70.1 \%)$ \\
\hline I change gloves between contacts with different patients & $18(6.6 \%)$ & $61(22.3 \%)$ & $195(71.2 \%)$ \\
\hline I avoid wearing my gown out of hospital compounds & $19(6.9 \%)$ & $35(12.8 \%)$ & $220(80.3 \%)$ \\
\hline $\begin{array}{l}\text { I wear a waterproof apron whenever there is a possibility of body } \\
\text { fluid }\end{array}$ & $96(35.0 \%)$ & $70(25.5 \%)$ & $108(39.4 \%)$ \\
\hline $\begin{array}{l}\text { I wear eye goggles whenever there is a possibility of body fluid } \\
\text { splashing }\end{array}$ & $111(40.5 \%)$ & $59(21.5 \%)$ & $104(38.0 \%)$ \\
\hline
\end{tabular}




\section{Epidemiology international journal}

\begin{tabular}{|c|c|c|c|}
\hline $\begin{array}{l}\text { I sterilize all reusable equipment before being used on another } \\
\text { patient }\end{array}$ & $46(16.8 \%)$ & $43(15.7 \%)$ & $185(67.5 \%)$ \\
\hline I clean and disinfect equipment and environmental surfaces & $36(13.1 \%)$ & $39(14.2 \%)$ & $199(72.6 \%)$ \\
\hline I segregate noninfectious wastes in black colour coded dust bin & $22(8.0 \%)$ & $38(13.9 \%)$ & $214(78.1 \%)$ \\
\hline $\begin{array}{l}\text { I segregate infectious medical wastes in yellow coloured coded dust } \\
\text { bin }\end{array}$ & 15 & 0) & 20 \\
\hline I never bend needles with my hands & $23(8.4 \%)$ & $46(16.8 \%)$ & $205(74.8 \%)$ \\
\hline I avoid removing used needles from disposable syringes & $22(8.0 \%)$ & $38(13.9 \%)$ & $214(78.1 \%)$ \\
\hline I place used sharps in puncture-resistant container at point of use & $13(4.7 \%)$ & $44(16.1 \%)$ & $217(79.2 \%)$ \\
\hline I never recap needles & $30(10.9 \%)$ & $54(19.7 \%)$ & $190(69.3 \%)$ \\
\hline
\end{tabular}

Table 2: Compliance level with infection prevention guidelines among health care workers in Hospitals of Hadiya zone, Southern Ethiopia, July, 2017 (N=274).

\section{Observed Compliance with IP Guidelines}

Hand hygiene: Out of the 51 observed participants for IP practices, more than half (58.8\%) did hand hygiene by washing with water and soap or using alcohol based hand rub before and after performing any procedure and only one third of the participants (66.7\%) wash hands before putting on gloves and after removing gloves. 92.2\% observed participants wash hands after handling contaminated objects. Less than half $(39.2 \%)$ perform hand hygiene before preparing medication (Figure 2).

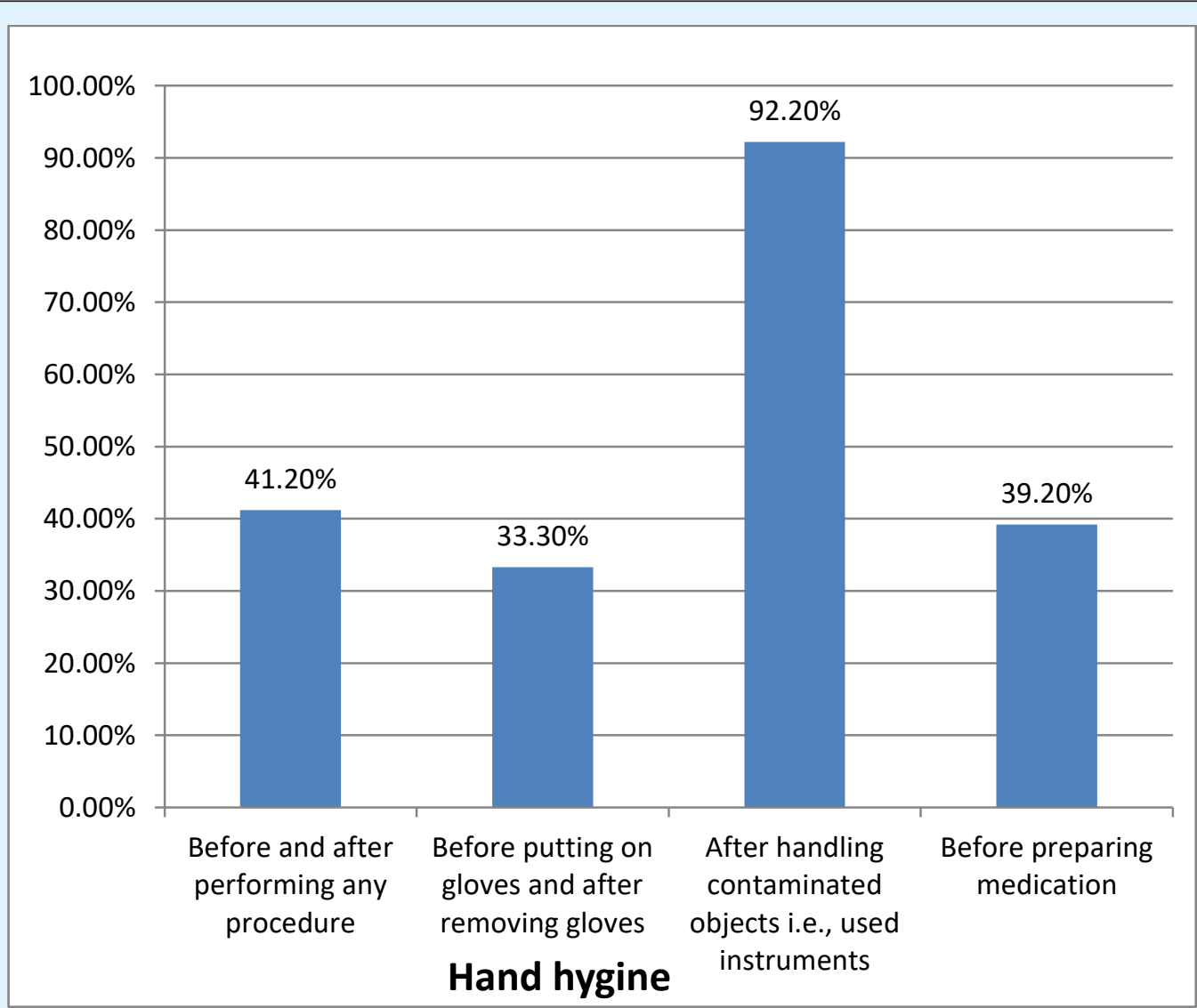

Figure 2: Observed Compliance level with hand hygiene among health care workers in Hospitals of Hadiya zone, Southern Ethiopia, July, 2017 ( $\mathrm{N}=51)$.

Use of PPE: From the observed participants almost all (98\%) worn gowns during procedures when contact with blood or body fluids is anticipated and during procedures which are likely to generate splashes or sprays of blood or other body fluids but only about half (54.9\%) used Mouth, nose and eye protection (figure 3). 


\section{Epidemiology international journal}

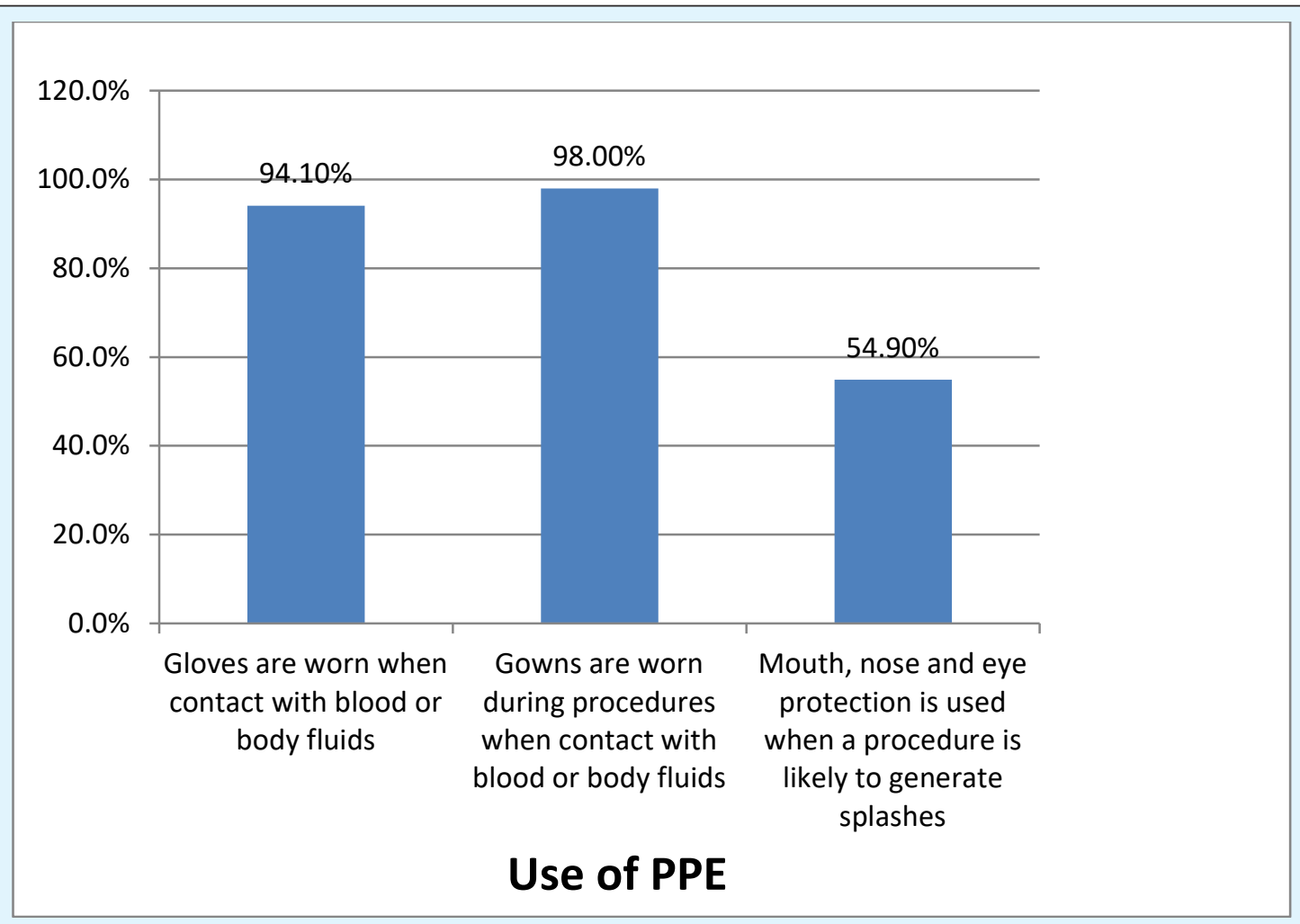

Figure 3: Observed Compliance level with use of PPE among health care workers in Hospitals of Hadiya zone, Southern Ethiopia, July, 2017 ( $\mathrm{N}=51)$.

\section{Instrument Processing}

From the observed 51 health care workers, $45(88.2 \%)$ decontaminated Used instruments immediately after use by soaking in $0.5 \%$ chlorine for 10 minutes and then washed in soapy water, then rinsed in clean water and dried before sending them for high level disinfection or sterilization.

\section{Waste Management}

$90.2 \%$ of the observed participants did not recap or bend needles after use and both needle and syringe are immediately disposed of into a puncture resistant container and $76.5 \%$ segregated Solid waste at point of use according to category (Table 3).

\begin{tabular}{|c|c|c|}
\hline Variable & Number & \% \\
\hline Waste management & & \\
\hline Needles are not recapped or bent after use and both needle and syringe & 46 & 90.2 \\
\hline Puncture resistant containers for sharps are disposed of when 3/4 full & 47 & 92.2 \\
\hline Solid waste is segregated at point of use according to category & 39 & 76.5 \\
\hline Contaminated waste is disposed of into a container with a plastic liner & 46 & 90.2 \\
\hline Waste containers are disposed of when 3/4 full & 46 & 90.2 \\
\hline
\end{tabular}

Table 3: Observed Compliance level with waste management among health care workers in Hospitals of Hadiya zone, Southern Ethiopia, July, 2017 ( $\mathrm{N}=51$ ).

\section{Individual Factors}

From the participants included in this study, 91.6\% and $90.1 \%$ of the respondents heard about infection prevention guide lines and Health facilities acquired infections, respectively from different sources. With respect to knowledge on infection prevention guidelines, $93.8 \%$ of the respondents were knowledgeable. From the respondents, 86.9\%, 90.1\%,
89.1\% 90.5\% and 90.1\% knew airborne, contact with blood and body fluid, contaminated instruments and contaminated hands as mode of transmission for $\mathrm{HAI}$, respectively. As prevention means of HAI, 96.4\% knew Instrument processing and $88.3 \%$ knew isolation. From the HCWs included in this study, more than half (51.5\%) ever had no training on infection prevention (Table 4). 
Out of 274 respondents, $180(65.7 \%)$ had positive attitude and $94(34.3 \%)$ had negative attitude towards infection prevention guide lines.

\begin{tabular}{|c|c|c|}
\hline Variable & Number & $\%$ \\
\hline Ever heard about infection prevention guide lines & 251 & 91.6 \\
\hline Ever heard about Health facilities acquired infections & 247 & 90.1 \\
\hline Ever had training on infection prevention & 133 & 48.5 \\
\hline Which mode of transmission of HAI do you know & & \\
\hline Air borne & 238 & 86.9 \\
\hline Contact with blood and body fluid & 244 & 89.1 \\
\hline Needle sticks & 244 & 89.1 \\
\hline Contaminated instruments & 248 & 90.5 \\
\hline Contaminated hands & 247 & 90.1 \\
\hline Prevention means of HAI HCWs know & 258 & \\
\hline Hand hygiene & 261 & 94.2 \\
\hline Use of personal Protective equipment & 263 & 96.3 \\
\hline Proper disposal of medical waste & 264 & 96.4 \\
\hline processing of instruments & 242 & 88.3 \\
\hline
\end{tabular}

Table 4: Individual factors among health care workers in Hospitals of Hadiya zone, Southern Ethiopia, July, 2017 $(\mathrm{N}=274)$.

\section{Institutional Factors}

Out of the health care workers, $56.9 \%$ replied that there was availability of PPE in their health facility and $56.0 \%$ had access to these PPE. More than half (56.6\%) did not get management support for safety. Majority $(63.1 \%)$ replied that management provides feedback for safety practices less frequently. Concerning accessibility of IP guidelines, for $51.8 \%$ IP guidelines were not readily accessible (Table 5 ).

\begin{tabular}{|c|c|c|}
\hline Variables & Number & \% \\
\hline PPE availability & 156 & 56.9 \\
\hline PPE accessibility & 148 & 56.0 \\
\hline Management support for safety & 119 & 43.5 \\
\hline $\begin{array}{c}\text { Management provide Feedback } \\
\text { for safety practice }\end{array}$ & 101 & 36.9 \\
\hline $\begin{array}{c}\text { Presence of training on IP } \\
\text { Guidelines }\end{array}$ & 98 & 35.8 \\
\hline Accessibility of IP Guidelines & 132 & 48.2 \\
\hline
\end{tabular}

Table 5: Institutional factors among health care workers in Hospitals of Hadiya zone, Southern Ethiopia, July, $2017(\mathrm{~N}=274)$.

\section{Factors Associated with Compliance with IP Guidelines}

Result of bivariate analysis showed that sex $(p<0.005)$, marital status $(p=0.001)$, work experience $(p=0.010)$ attitude of the respondents towards IP guidelines $(p<0.010)$, availability of PPE $(p<0.05)$, accessibility of PPE $(\mathrm{P}<0.005)$, management support for safety $(p<0.010)$ and presence of training on IP guidelines $(\mathrm{P}=0.001)$ were identified as candidates for multivariate analysis at p-value $<0.05$ (Table 6).

In multivariate logistic regression analysis, attitude towards IP guidelines, access to PPE and presence of training were significantly associated with compliance with infection prevention guide lines (Table 6).

Female health care workers were about 3 times more compliant to infection prevention guidelines as compared to males (AOR: 2.962, 95\%CI: $(1.342,6.535)$ ).

Respondents who had positive attitude towards IP guidelines were 3 times more likely to had compliance with IP guidelines as those who had negative attitude (AOR: 3.130, 95\%CI: $(1.192,8.224)$ ). 
The odds of having compliance to IP guide lines was 2.5 times higher on those health care workers who had access to IP guidelines as those who had no access to IP guidelines (AOR: 2.820, 95\%CI: (1.076,7.389)).
Health care workers who had training on IP guidelines were 2.3 times more likely to comply with IP guidelines as compared to those who had no training (AOR: 2.262, 95\%CI: $(1.008,5.078)$.

\begin{tabular}{|c|c|c|c|}
\hline \multirow[b]{2}{*}{ Variables } & \multicolumn{3}{|c|}{ Compliance level ( $\mathrm{N}$ and $\%$ ), $\mathrm{N}=274$} \\
\hline & seldom & Sometimes & Always \\
\hline Wash hands before touching a patient & $68(24.8 \%)$ & $110(40.1 \%)$ & $96(35.0 \%)$ \\
\hline Wash hands before clean or aseptic procedures & $37(13.5 \%)$ & $94(34.3 \%)$ & $143(52.2 \%)$ \\
\hline Wash hands after body fluid exposure & $15(5.5 \%)$ & $54(19.7 \%)$ & $205(74.8 \%)$ \\
\hline Wash hands after touching a patient & $40(14.6 \%)$ & $118(43.1 \%)$ & $116(42.3 \%)$ \\
\hline Wash hands immediately after removal of gloves & $60(21.9 \%)$ & $115(42.0 \%)$ & $99(36.1 \%)$ \\
\hline Wash hands between patient contact & $67(24.5 \%)$ & $122(44.5 \%)$ & $85(31.0 \%)$ \\
\hline Wash hands after touching patient surroundings & $54(19.7 \%)$ & $117(42.7 \%)$ & $103(37.6 \%)$ \\
\hline I provide care considering all patients as potentially infectious & $27(9.9 \%)$ & $105(38.3 \%)$ & $142(51.8 \%)$ \\
\hline $\begin{array}{l}\text { I protect myself against body fluids of all patients regardless of their } \\
\text { diagnosis }\end{array}$ & $12(4.4 \%)$ & $86(31.4 \%)$ & $176(64.2 \%)$ \\
\hline $\begin{array}{l}\text { I wear clean gloves whenever there is a possibility of exposure to any } \\
\qquad \text { body fluids }\end{array}$ & $10(3.6 \%)$ & $72(26.3 \%)$ & $192(70.1 \%)$ \\
\hline I change gloves between contacts with different patients & $18(6.6 \%)$ & $61(22.3 \%)$ & $195(71.2 \%)$ \\
\hline I avoid wearing my gown out of hospital compounds & $19(6.9 \%)$ & $35(12.8 \%)$ & $220(80.3 \%)$ \\
\hline $\begin{array}{l}\text { I wear a waterproof apron whenever there is a possibility of body } \\
\text { fluid }\end{array}$ & $96(35.0 \%)$ & $70(25.5 \%)$ & $108(39.4 \%)$ \\
\hline $\begin{array}{l}\text { I wear eye goggles whenever there is a possibility of body fluid } \\
\text { splashing }\end{array}$ & $111(40.5 \%)$ & $59(21.5 \%)$ & $104(38.0 \%)$ \\
\hline $\begin{array}{l}\text { I sterilize all reusable equipment before being used on another } \\
\qquad \text { patient }\end{array}$ & $46(16.8 \%)$ & $43(15.7 \%)$ & $185(67.5 \%)$ \\
\hline I clean and disinfect equipment and environmental surfaces & $36(13.1 \%)$ & $39(14.2 \%)$ & $199(72.6 \%)$ \\
\hline I segregate noninfectious wastes in black colour coded dust bin & $22(8.0 \%)$ & $38(13.9 \%)$ & $214(78.1 \%)$ \\
\hline $\begin{array}{l}\text { I segregate infectious medical wastes in yellow coloured coded dust } \\
\text { bin }\end{array}$ & $15(5.5 \%)$ & $53(19.3 \%)$ & $206(75.2 \%)$ \\
\hline I never bend needles with my hands & $23(8.4 \%)$ & $46(16.8 \%)$ & $205(74.8 \%)$ \\
\hline I avoid removing used needles from disposable syringes & $22(8.0 \%)$ & $38(13.9 \%)$ & $214(78.1 \%)$ \\
\hline I place used sharps in puncture-resistant container at point of use & $13(4.7 \%)$ & $44(16.1 \%)$ & $217(79.2 \%)$ \\
\hline I never recap needles & $30(10.9 \%)$ & $54(19.7 \%)$ & $190(69.3 \%)$ \\
\hline
\end{tabular}

Table 6: Factors associated with compliance with IP guidelines in Hospitals of Hadiya zone, Southern Ethiopia, July, 2017.

Significant at $\mathrm{p}<0.001^{*} ; \mathrm{p}<0.01^{* *} ; \mathrm{p}<0.05^{* * *}$

$\mathrm{PPE}=$ Personal protective Equipments, $\mathrm{CI}=$ Confidence Interval, $\mathrm{IP}=$ Infection Prevention 


\section{Discussion}

This study was conducted on 274 health-care workers to assess compliance level with Infection Prevention Guidelines and associated factors in Hospitals of Hadiya Zone, Southern Ethiopia.

The findings of the study showed that the overall compliance of HCWs with infection prevention guidelines was $15.0 \%$ (95\%CI: $11.0 \%, 19.0 \%)$. This finding is in line with the findings of study Gondar University Comprehensive Specialized Hospital, Northwest Ethiopia which showed overall compliance of $12 \%$ [14]. Even though the overall compliance of HCWs with infection prevention guidelines is very low, when specific components of the IP guidelines was analyzed better compliance was recorded in some of the items. A relatively higher proportion of HCWs were found to be always compliant with Wash hands after body fluid exposure (74.8\%), wear clean gloves whenever there is a possibility of exposure to any body fluids $(70.1 \%)$, changing gloves between contacts with different patients (71.2\%), clean and disinfect equipment and environmental surfaces (72.6\%) and placing used sharps in puncture-resistant container at point of use (79.2\%).

In contrary, relatively low compliance was recorded in Wash hands before touching a patient (35.0\%), Wash hands between patient contact $(31.0 \%)$, Wash hands immediately after removal of gloves (36.1\%) and Wash hands after touching patient surroundings (37.6\%) These findings were nearly similar to findings of study done in Gondar University Comprehensive Specialized Hospital, Northwest Ethiopia [14]. However, there is improvement in hand washing practice in this study as compared to study conducted in Mbagathi district hospital, Nairobi, Kenya in which only 5.6\% Wash hands between patient contact and $3.3 \%$ of the participants wash hands before putting and after removing gloves [16]. This difference might be due to presence of regular training, accessibility of PPE and better management support on safety for the participants of current study.

The current study revealed that female health care workers were about 3 times more compliant to infection prevention guidelines as compared to males. This result is in line with the findings of study done in Gondar University Comprehensive Specialized Hospital, Northwest Ethiopia, in which females were 2.2 folds more complaint as compared to males [14]. The compliance difference in sex might be due to the females' natural ability to obey rules and regulations. In Ethiopia, females have more responsibility to care for family in that they might be more careful not to bring health problems to their family.
In this study, respondents who had positive attitude towards IP guidelines were 3 times more likely to had compliance with IP guidelines as those who had negative attitude. This result similar with the findings of study done in Gondar University Comprehensive Specialized Hospital, Northwest Ethiopia which showed that that HCWs who had higher perception of infection risk were about 3.5 times more likely to always comply with standard precautions than those who had lower perception of risk. The finding is also similar to study conducted in Mbagathi district hospital, Nairobi, Kenya $[14,16]$. But it is in contrary to study conducted at Ronald Ross General Hospital Mufulira District, Zambia which showed low level of compliance was not due to negative attitude [17]. This difference might be due to the cultural differences in the two countries and the difference in up-to- date knowledge and skill regarding infection prevention guidelines among Health care workers.

This study showed that the odds of having compliance to IP guide lines was about 3 times higher on those health care workers who had access to IP guidelines as those who had no access to IP guidelines. This result is in consistency with the findings of study done in Gondar University Comprehensive Specialized Hospital, Northwest Ethiopia, in which HCWs who had access to PPE were 3 times more complaint as those who had no access [14]. The finding is also similar to study conducted in Ronald Ross General Hospital Mufulira District, Zambia [17].

Health care workers who had training on IP guidelines were 2.3 times more likely to comply with IP guidelines as compared to those who had no training. This finding is in line with the findings of study done in Gondar University Comprehensive Specialized Hospital, Northwest Ethiopia and study conducted in Ronald Ross General Hospital Mufulira District, Zambia [14,17].

\section{Limitation of the study}

This study has the following limitations:

As being cross-sectional in the design, this study lacks to show temporal relationship between cause and effect. Moreover, out of the 274 participated health care workers, only 51 were observed on their infection prevention practices. This could have biased the results since some of the participants who were not observed could have had some unusual IP practices.

\section{Conclusion}

In this study the overall compliance level of the health care workers to infection prevention guide lines was very low. Being female, attitude towards infection prevention guidelines, accessibility of personal 
protective equipments and training on infection guidelines were factors significantly associated with compliance with infection prevention guidelines. Continuous training on infection prevention guidelines should be given to health care workers, especially for males. Accessibility of infection prevention materials and equipments in the hospitals should get due attention.

\section{Declarations}

\section{Ethics Approval and Consent to Participate}

Ethical clearance was obtained from ethics review committee of Hossana College of health sciences. Permission letter was obtained from hospitals of Hadiya Zone. Other concerned bodies of the health facilities were also informed about the study. All the information retrieved was kept in the way that could not interfere in personal confidentiality. Informed consent was obtained from each study participant after explanation of the purpose of the study. All sample populations were encouraged to participate in the study while at the same time they were told their right not to participate. Healthcare workers who exposed to potentially infected body fluids during the data collection period were provided with first aid and referred to infection prevention committee of the hospitals for better management and follow-up.

\section{Consent for Publication}

"Not applicable" in this section.

\section{Funding}

The study was fully funded by Hosanna College of Health Sciences. The college also provided experts for supervisory, advisory and facilitation activities during the study period.

\section{Availability of Data and Materials}

The authors do not have full mandate to share the data since they are the property of the funding institution.

\section{Competing Interests}

The authors declare that they have no competing interests.

\section{Acknowledgements}

We would like to forward our great thanks to Hossana college of Health Science for giving us this golden opportunity to develop this research proposal. We would also like to thank Wachemo University Nigist
Ellen Mohammed Memorial General hospital, Shone and Homecho district hospitals for providing relevant information for this research activity. Lastly, our gratitude goes to all individuals who participated in giving us all the relevant information for this research process.

\section{Authors' Contributions}

TY conceived the research idea, conducted the data collection, data analysis and data interpretation, and wrote and reviewed the paper. GK conducted the data collection, data analysis and data interpretation, and reviewed the paper. TL and EG approved the proposal, participated in data analysis and revised subsequent draft of the paper. All authors read and approved the final paper.

\section{References}

1. Bouvet E (1993) Risk for health professionals of infection with human immunodeficiency virus. Current knowledge and developments in preventive measures. Medicine at Maladies Infectiousness 23: 28-33.

2. CDC (2010) Recommendations for prevention of transmission of Immune Deficiency Virus and Hepatitis B Virus to health care and public safety workers. MMWR 38.

3. Zingg W, Holmes A, Dettenkofer M, Goetting T, Secci F, et al. (2015) Hospital organisation, management, and structure for prevention of health-care associated infection: a systematic review and expert consensus. The Lancet Infectious Diseases journal 15(2): 212-224.

4. Alvarado CJ (2000) The Science of Hand Hygiene: A Self-Study Monograph. University of Wisconsin Medical School and Sci-Health Communications.

5. March Kohn LT, Corrigan JM, Donaldson MS (2000) To err is human: building a safer health system. A report of the Committee on Quality of Health Care in America, Institute of Medicine. National Academy Press, Washington, DC.

6. Taylor G, Gravel D, Matlow A, Embree J, LeSaux N, et al. (2016) Assessing the magnitude and trends in hospital acquired infections in Canadian hospitals through sequential point prevalence surveys. Antimicrobial Resistance and Infection Control Journal 5: 19.

7. Klevens RM, Edwards JR, Richards CL Jr, Horan TC, Gaynes RP, et al. (2007) Estimating health care- 


\section{Epidemiology international journal}

associated infections and deaths in U.S. Hospitals. Public Health Reports 122(2): 160-166.

8. Bagheri Nejad S, Allegranzi B, Syed SB, Ellis B, Pittet D (2011) Health-care-associated infection in Africa: a systematic review. Bulletin of the World Health Organization 89(10): 757-765.

9. WHO (2002) Report on reducing risks, promoting health life. World Health Organization, Geneva, Switzerland.

10. Lynch P (1997) Infection prevention with limited Resources. ETNA communications.

11. Phipps W, Honghong W, Min Y, Burgess J, Pellico L, et al. (2002) Risk of medical sharps injuries among Chinese nurses. Am J Infect Control 30(5): 277-282.

12. Allegranzi B, Sax H, Bengaly L, Richet H, Minta DK, et al. (2010) World Health Organization project management: successful implementation of the world Health Organization hand hygiene improvement strategy in referral hospital in Mali, Africa. Infect Control Hosp Epidemiol 31(2): 133141.
13. Mengesha RE, Kasa BG, Saravanan M, Berhe DF, Wasihun AG (2014) Aerobic bacteria in post surgical wound infections and pattern of their antimicrobial susceptibility in Ayder Teaching and Referral Hospital, Mekelle, Ethiopia. BMC Research Notes 7(1): 575.

14. Haile TG, Engeda EH, Abdo AA (2017) Compliance with Standard Precautions and Associated Factors among Healthcare Workers in Gondar University Comprehensive Specialized Hospital, Northwest Ethiopia. Journal of Environmental and Public Health, pp: 8 .

15. FMOH (2000) Prevention D. Infection prevention for Healthcare Facilities in Ethiopia. Addis Ababa.

16. Gertrude Munthali Moyo (2013) Factors Influencing Compliance with Infection Prevention Standard Precautions among Nurses Working at Mbagathi District Hospital, Nairobi, University Of Nairobi, Kenya.

17. Mukwato KP, Ngoma CM, Maimbolwa M (2007) Compliance with Infection Prevention Guidelines By Health Care Workers At Ronald Ross General Hospital Mufulira District 35(3). 